\title{
Neonatal pulse oxymetry as a screening for congenital heart disease: single or double recordings?
}

\author{
Luca Rosti
}

Received: 1 July 2010 / Accepted: 14 July 2010 / Published online: 28 July 2010

(C) Springer-Verlag 2010

The paper by Riede et al. demonstrates further the usefulness and effectiveness of pulse oxymetry screening (POS) in the detection of critical congenital heart defects (cCHDs) by measuring oxygen saturation (SpO2) at 1 foot. They detected 14 neonates with cCHDs but missed four with cCHD, which is approximately one fourth of the patients with critical defects [2]. Single-site $\mathrm{SpO} 2$ is recommended even by the AHA and the AAP, but we may not rule out that at least one of the four infants "missed" by the authors could be identified with the adoption of a two-site recording (right arm and 1 foot) [1]. Actually, some cCHDs may be missed by the single-site POS because $\mathrm{SpO} 2$ may be higher (i.e. close to normal) in the legs than in the right arm and because pulmonary artery $\mathrm{SpO} 2$ are higher than in the aortic arch - this may happen with d-transposition of the great arteries in the first few days of life in Taussig-Bing anomaly, in total anomalous pulmonary drainage into superior vena cava and in infants with truncus arteriosus with interrupted aortic arch. In all these cCHDs, the higher $\mathrm{SpO} 2$ in the legs depends on the ductal shunting of (more) oxygenated blood to the descending aorta than to the aortic arch [3]. It is of note that these cCHDs are among those which may benefit more from prompt diagnosis and treatment. Therefore, despite the risk of increasing the number of false positives, it has been suggested that two-site POS may increase sensibility of the screening up to $92 \%$.

Finally, whether aortic coarctation may escape POS screening depends probably on the "dynamic" behaviour of this CHD, whose signs and symptoms appear when the ductus arteriosus begins to close- this underscores the need for an outpatient evaluation of "all" the neonates within 23 days after discharge home, with routine evaluation of peripheral pulses.

\section{References}

1. Mahle WT, Newburger JW, Matherne GP, Smith FC, Hoke TR, Kopple R, Gidding SS, Beckman RH 3rd, Grosse SD (2009) Role of pulse oxymetry in examining newborns for congenital heart disease: a scientific statement from the AHA and the AAP. Pediatrics 124:823-836

2. Riede FT, Worner C, Dahnert I, Mockel A, Kostelka M, Schneider P (2010) Effectiveness of pulse oxymetry screening for detection of critical congenital heart disease in daily clinical routine-results form a prospective multicenter study. Eur J Pediatr 169:975-981

3. Rudolph A (2009) Oxygen uptake and delivery. In: Congenital diseases of the heart. Oxford, Blackwell Publishing, pp 39-41

L. Rosti $(\bowtie)$

Neonatology, Ospedale San Giuseppe,

Via San Vittore 12,

20123 Milan, Italy

e-mail: luca.rosti@multimedica.it

L. Rosti

Pediatric Cardiology, IRCCS San Donato,

Via Morandi 30,

20097 San Donato Milanese, Italy 